\title{
Systemic Inflammation Is Associated With Longitudinal Changes in Cognitive Performance Among Urban Adults
}

\author{
May A. Beydoun ${ }^{1 *}$, Gregory A. Dore ${ }^{1}$, Jose-Atilio Canas ${ }^{2}$, Hailun Liang ${ }^{3}$, \\ Hind A. Beydoun ${ }^{4}$, Michele K. Evans ${ }^{1 \dagger}$ and Alan B. Zonderman ${ }^{1+}$ \\ ${ }^{1}$ Laboratory of Epidemiology and Population Sciences, National Institute on Aging (NIA), National Institutes of Health \\ Intramural Research Program, Baltimore, MD, United States, ${ }^{2}$ Johns Hopkins All Children's Hospital, St. Petersburg, FL, \\ United States, ${ }^{3}$ Institute on Social Welfare, Renmin University of China, Beijing, China, ${ }^{4}$ Department of Medicine, Johns \\ Hopkins School of Medicine, Baltimore, MD, United States
}

\section{OPEN ACCESS}

Edited by: Thomas Wolbers, Helmholtz-Gemeinschaft Deutscher Forschungszentren (HZ), Germany

Reviewed by: Regina Dahlhaus, Friedrich-Alexander-Universität Erlangen-Nürnberg, Germany Steven Bradburn, Manchester Metropolitan University, United Kingdom

*Correspondence: May A. Beydoun baydounm@mail.nih.gov

${ }^{t}$ These authors share senior authorship

Received: 11 June 2018 Accepted: 18 September 2018 Published: 09 October 2018

Citation:

Beydoun MA, Dore GA, Canas J-A, Liang $H$, Beydoun HA, Evans MK and Zonderman AB (2018) Systemic Inflammation Is Associated With Longitudinal Changes in Cognitive Performance Among Urban Adults. Front. Aging Neurosci. 10:313. doi: 10.3389/fnagi.2018.00313
Objectives/Background: Systemic inflammation can affect cognitive performance over time. The current study examined associations between systemic inflammation and cognitive performance among African Americans and Whites urban adults, stratifying by sex, and age group and by race.

Patients/Methods: Among 1,555-1,719 White and African-American urban adults

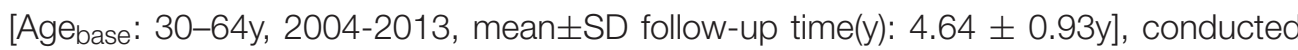
linear mixed-effects regression models were conducted to test associations of inflammatory markers [C-reactive protein, Erythrocyte Sedimentation Rate (ESR), albumin, iron, and an inflammation composite score (ICS)] with longitudinal cognitive performance.

Results: Among key findings, CRP was linked to poorer baseline mental status among younger women $\left(\leq 50 \mathrm{y}, \gamma_{01}=-0.03 \pm 0.01, p=0.002\right)$ and poorer attention in older women ( $\left.>50 \mathrm{y}, \gamma_{01}=-0.024 \pm 0.007, p<0.004\right)$ and African-Americans $\left(\gamma_{01}=-0.029 \pm 0.008, p<0.001\right)$. ESR was related to faster decline on verbal memory among older men ( $>50 y, \gamma_{11}=-0.008 \pm 0.003, P=0.009$ ); with poorer performance on attention tests overall $\left(\gamma_{01}=-0.010 \pm 0.003, P=0.003\right)$ and among African-Americans ( $\left.\gamma_{01}=-0.013 \pm 0.004, P=0.002\right)$; on verbal fluency among older women $\left(>50 \mathrm{y}, \gamma_{01}=-0.037 \pm 0.013, P=0.004\right)$ and on executive function: overall $\left(\gamma_{01}=+0.62 \pm 0.21, P=0.004\right)$, older men $\left(>50 y, \gamma_{01}=+1.69 \pm 0.53, P=0.001\right)$ and African-Americans $\left(\gamma_{01}=+0.84 \pm 0.28, P=0.002\right)$. Albumin was linked to slower attention decline among older men ( $\left.>50 y, \gamma_{11}=+0.329 \pm 0.103, P=0.009\right)$, over-time improvement in executive function overall $\left(\gamma_{11}=-6.00 \pm 2.26, P=0.008\right)$, and better baseline psychomotor speed among African-Americans $\left(\gamma_{01}=+0.56 \pm 0.19, P=0.003\right)$. Finally, ICS predicted faster decline on visual memory/visuo-constructive abilities among older men (>50y, $\gamma_{11}=+0.17 \pm 0.06, p=0.003$ ).

Conclusion: In sum, strong associations between systemic inflammation and longitudinal cognitive performance were detected, largely among older individuals (>50y) and African-Americans. Randomized trials targeting inflammation are warranted.

Keywords: inflammation, serum biomarkers, C-reactive protein (CRP), cognitive performance, urban adults 


\section{INTRODUCTION}

Chronic systemic inflammation is a risk for neurodegeneration manifesting as Alzheimer's Disease (AD) and age-related cognitive decline. Markers of inflammation are associated with poorer cross-sectional cognitive performance, faster longitudinal decline in various domains of cognition (Lai et al., 2017; Stacey et al., 2017) as well as with structural and functional brain changes representing early markers of $\mathrm{AD}$, including brain region activity, regional cortical thickness and white matter microstructural integrity (Jefferson et al., 2007; Hoshi et al., 2010; Wersching et al., 2010; Wada et al., 2011; Bettcher et al., 2012; Satizabal et al., 2012; Arfanakis et al., 2013; Taki et al., 2013; Walker et al., 2017; Corlier et al., 2018; Gu et al., 2018; Warren et al., 2018). However, few studies have examined cross-sectional or longitudinal associations of inflammation with cognitive performance in a bi-racial adult cohort (Yaffe et al., 2003; Windham et al., 2014; Goldstein et al., 2015; Walker et al., 2017), and none have tested effect modification by race, age, and sex in the relationship between systemic inflammation and rate of change in cognitive performance over time while using a large battery of cognitive tests.

Acute-phase markers such as C-reactive protein (CRP) increase over 1,000-folds during inflammation induced by infection, trauma, surgery, burns, tissue infarction, various immunologically mediated, and advanced cancer (Gabay and Kushner, 1999). Others including complement system proteins and ceruloplasmin increase only by $\sim 50 \%$ (Gabay and Kushner, 1999). These changes in acute phase marker concentrations are largely due to their modified liver production (Gabay and Kushner, 1999). At higher does, CRP was shown to increase the paracellular permeability at the blood brain barrier, in the context of leptin resistance (Hsuchou et al., 2012). In contrast, cytokines are intercellular signaling polypeptides produced by activated cells, including macrophages and monocytes (Gabay and Kushner, 1999). Each cytokine has multiple sources, functions and targets, and operates both within a cascade and a network (Gabay and Kushner, 1999). Among cytokines, interleukin-6 (IL-6) is the chief stimulator of acute-phase protein production, including CRP (Gabay and Kushner, 1999). While CRP, IL-6 and other key cytokines are the focus of most recent epidemiological investigations (Bettcher et al., 2012; Satizabal et al., 2012; Trollor et al., 2012; Arfanakis et al., 2013; O’bryant et al., 2013; Taki et al., 2013; Yarchoan et al., 2013; Krogh et al., 2014; Lima et al., 2014; Metti et al., 2014; Windham et al., 2014; Goldstein et al., 2015; Matsushima et al., 2015; Palta et al., 2015; Gong et al., 2016; Tampubolon, 2016; Tegeler et al., 2016;

Abbreviations: AD, Alzheimer's Disease; AF, Animal Fluency test; ALB, Albumin; BTA, Brief Test of Attention; BVRT, Benton Visual Retention Test; CDT, Clock Drawing Test; CES-D, Center for Epidemiologic Studies-Depression; CVLTDFR, California Verbal Learning Test, Delayed Free Recal; (List A); CVLT-List A, California Verbal Learning Test, immediate recall (List A); CRP, C-reactive protein; DS-B, Digit Span Backwards; DS-F, Digit Span Forward; HANDLS, Healthy Aging in Neighborhoods of Diversity Across the Life Span; hs-CRP, High sensitivity C-reactive protein; HS, High School; IL, Interleukin; OLS, Ordinary Least Square; PIR, Poverty Income Ratio; Trails A, Trailmaking test, Part A; Trails B, Trailmaking test, Part B; WBC, White Blood Cells; WRAT, Wide Range Achievement Test.
Watanabe et al., 2016; Hsu et al., 2017; Lai et al., 2017; Walker et al., 2017; Corlier et al., 2018; Hajjar et al., 2018; Warren et al., 2018), systemic inflammation is accompanied by other changes including an increased level of fibrinogen (Gabay and Kushner, 1999; Van Oijen et al., 2005; Luciano et al., 2009; Marioni et al., 2009; Wada et al., 2011; Tampubolon, 2016), a rise in white blood cell (WBC) counts (Warren et al., 2018) and a reduction in albumin (or microalbuminuria) (Gabay and Kushner, 1999; Dik et al., 2005; Kuo et al., 2007; Vupputuri et al., 2008; Ng et al., 2009; Llewellyn et al., 2010; Onem et al., 2010; Taniguchi et al., 2014; Koyama et al., 2016; Murayama et al., 2017; Walker et al., 2017; Warren et al., 2018), and transferrin (or iron status measures) concentrations (Onem et al., 2010; Taniguchi et al., 2014; Murayama et al., 2017). Thus, a composite score summarizing inter-correlated changes is warranted yielding a clearer picture of the association between systemic inflammation and cognitive outcomes.

The current study examined associations between systemic inflammation and cognitive performance among African Americans and Whites urban adults participating in the Health Aging in Neighborhoods of Diversity across the Life Span (HANDLS) study. Markers known to either increase or decrease during inflammation (Gabay and Kushner, 1999; Walker et al., 2017) were tested against cross-sectional and longitudinal cognitive function, stratifying by key socio-demographic factors, including age, sex, and race.

\section{MATERIALS AND METHODS \\ Database and Study Participants}

Initiated in 2004, HANDLS is a prospective cohort study focusing on the cardiovascular and cognitive health of an ethnically and socio-economically diverse urban population. The study used area probability sampling to recruit a socioeconomically diverse group of African American and White urban adults (baseline age: 30-64y) who resided in thirteen Baltimore city, MD neighborhoods (Evans et al., 2010). The present study included data from the baseline visit 1 (2004-2009) and the first follow-up examination (visit 2; 2009-2013), with followup time ranging between $<1$ and $\sim 8 \mathrm{y}$, mean \pm SD of $4.64 \pm$ $0.93 y$. Data included a battery of cognitive tests measured at both visits and markers of inflammation measured at the baseline visit 1 , as well as numerous baseline or fixed covariates. The study obtained written informed consent from all participants who were additionally provided with a protocol booklet and a video explaining key study procedures. The National Institute on Environmental Health Sciences Institutional Review Board of the National Institutes of Health approved the study protocol. Moreover, the HANDLS staff and investigators are required to adhere to NIH's biosecurity and safety procedures. They receive mandatory annual refresher training. They are also inspected by NIH's safety officers and by medical records compliance officers. In addition, HANDLS staff and investigators use universal precautions in handling all biomaterials.

The initial sample of HANDLS included 3,720 participants (Phase I, visit 1). At Phase II of visit 1, participant examinations yielded data on biochemical indices and cognitive performance 
for a sub-set of the initial sample. Specifically, baseline CRP, erythrocyte sedimentation rate (ESR), albumin, and serum iron were available on 2,646, 2,709, 2,753, and 2,749 participants, respectively. Consequently, the main exposure [a composite of all 4 measures, inflammation composite score (ICS)] was available among 2,580 participants at baseline. Sample sizes varied for the cognitive tests. Consequently, we determined the size of the final analytic sample based on exposure and covariate nonmissingness at baseline and cognitive performance measure nonmissingness at either visit. Figure S1 describes sample selection for all exposures as well as the main composite exposure. The final analytic sample sizes ranged between 1,555 and 1,719 participants with $k=1.5-1.7$ observation/participant.

\section{Cognitive Assessment}

The present study assessed cognitive performance using 7 tests that yielded 11 test scores, tapping into 7 distinctive domains (Global, attention, learning/memory, executive function, visuo-spatial/visuo-construction ability, psychomotor speed, language/verbal): the Mini-Mental State Examination (MMSE), the California Verbal Learning Test (CVLT) immediate (List A) and Delayed Free Recall (DFR), Digit Span Forward and Backwards tests (DS-F and DS-B), the Benton Visual Retention Test (BVRT), Animal Fluency test (AF), Brief Test of Attention (BTA), Trails A and B and the Clock Drawing Test (CDT) (Supplemental Method 1). All participants were able to complete informed consent after being probed for understanding the protocol. Despite the lack of dementia diagnosis, all participants were screened using the MMSE as a global mental status test, which they completed successfully (total score $\geq 24$ ). In cases where MMSE was low ( $\sim 6.6 \%$ were $<24$ at visit 1 and $1.9 \%$ at visit 2), it was judged to be caused by poor literacy rather than being a sign of dementia.

\section{Measures of Inflammation and Composite Score}

All laboratory tests selected for this study were done at Quest Diagnostics, Chantilly, VA. Using $5 \mathrm{~mL}$ of refrigerated whole blood stored in lavender-top EDTA tube, the Erythrocyte Sedimentation Rate (ESR) was tested within $24 \mathrm{~h}$ of blood draw. The blood draw was done in the early morning in a fasting state before the participant was offered breakfast. This test used automated modified Westergren photochemical capillary stopped flow kinetic analysis. The Mayo clinic reports a reference of $0-22 \mathrm{~mm} / \mathrm{h}$ for men and $0-29 \mathrm{~mm} / \mathrm{h}$ for women. (https://www.mayoclinic.org/tests-procedures/sed-rate/ about/pac-20384797) and is considered a proxy measure for serum fibrinogen (Yin et al., 2017). Similarly, high sensitivity CRP (hs-CRP) was analyzed with an immunoturbidimeter (Siemens/Behring Nephelometer II), using $0.5-1 \mathrm{~mL}$ of plasma, with the range $1-10 \mathrm{mg} / \mathrm{dL}$ indicating average or high cardiovascular risk and $>10 \mathrm{mg} / \mathrm{dL}$ suggestive of an infection or a chronic inflammation. Using $0.5-1 \mathrm{~mL}$ sample of plasma prepared with heparin and refrigerated for up to 30 days, albumin was measured with spectrophotometry, with an expected reference range of 3.6-5.1 g/dL. Finally, for serum iron, $0.5-1 \mathrm{~mL}$ of fasting serum was collected, transported at room temperature (with heparin added) and refrigerated or frozen subsequently. Serum iron was also measured with spectrophotometry, with reference ranges for men aged $\geq 30 \mathrm{y}$ set at $50-180 \mathrm{mcg} / \mathrm{dL}$ and for women: $20-49 y(40-190 \mathrm{mcg} / \mathrm{dL})$ and $50+y(45-160 \mathrm{mcg} / \mathrm{dL})$. All markers were used as continuous untransformed variables in the main analysis. A summary score of inflammation, namely the $\mathrm{z}$ - inflammation composite score (ICS) combined all 4 individual measures using a principal components analysis extracting one component score (a $\mathrm{z}$-score) that explained $>40 \%$ of the total variance. The ICS was used in the main analysis.

\section{Covariates}

Covariates included in our main models were selected based on their well-known association with the outcome of interest, namely cognitive decline (Barnes and Yaffe, 2011). Among those covariates, socio-demographic characteristics included baseline age, sex, race (White vs. African American), marital status, educational attainment (<High School (HS); HS, $>\mathrm{HS}$ ) and poverty income ratio (PIR $<125 \%$ for "poor"). Age group was categorized as $>50$ vs. $\leq 50 \mathrm{y}$, when used as an effect modifier combined with sex, but was entered as a continuous variable in models. Lifestyle and health-related covariates included measured body mass index $\left(\mathrm{BMI}, \mathrm{kg} / \mathrm{m}^{2}\right)$, self-reported opiate, marijuana, or cocaine use ("current" vs. "never or former"), smoking status ("current" vs. "never or former"), and the Wide Range Achievement Test (WRAT) letter and word reading subtotal scores to measure literacy. (See Supplemental Method 1) Depressive symptoms, mainly affective depressed mood were measured using the 20-item Center for Epidemiological Studies-Depression scale (CES-D). Baseline CES-D total score was included in the analysis as a potential confounder in the association between inflammation and cognitive change or baseline performance. Overall dietary quality was assessed using the total score from the Healthy Eating Index (HEI-2010), based on two self-reported 24-h recalls administered at baseline. Steps for calculating HEI-2010 are outlined in: http://appliedresearch.cancer.gov/tools/hei/tools. html and http://handls.nih.gov/06Coll-dataDoc.html. Finally, first-visit self-reported history of type 2 diabetes, hypertension, dyslipidemia, cardiovascular disease (stroke, congestive heart failure, non-fatal myocardial infarction. or atrial fibrillation), inflammatory disease (multiple sclerosis, systemic lupus, gout, rheumatoid arthritis, psoriasis, Thyroid disorder. and Crohn's disease), and use of non-steroidal anti-inflammatory drugs (NSAIDs, prescription, and over-the-counter) over the past 2 weeks, were considered as covariates, as was done in previous studies (Gimeno et al., 2009; Bettcher et al., 2012).

\section{Statistical Analysis}

All analyses were carried out with Stata release 15.0 (STATA, 2017). Accounting for sampling weights, population means and proportions were estimated. While means across key stratifying variables (e.g., age/sex or race) were contrasted using svy:reg, comparisons between categorical variables were accomplished using svy:tab and design-based F-tests. The main analysis included a series of mixed-effects regression models with 11 continuous cognitive test score as outcomes. In each of those 
models, the TIME variable, expressed as years elapsed between data waves, was entered as a fixed and random effect (along with the intercept) and was interacted with several covariates including the main exposure variable, namely the inflammation composite score. All mixed-effects regression models assumed that the outcome was missing at random with repeated measures of $\sim 1.5-1.7$ visits/person and accounted for variable time of follow-up (See Supplemental Method 2) (Ibrahim and Molenberghs, 2009). Moreover, to visualize key findings from mixed-effects regression models, predictive margins of outcomes were estimated and plotted across TIME (y), stratifying by exposure levels $(-1=$ mean $-1 \mathrm{SD}, 0=$ mean, $+1=$ mean $+1 \mathrm{SD})$. Mixed-effects regression models were also conducted to test longitudinal associations of each of the 4 inflammation markers with the 11 continuous cognitive test scores.

Simultaneous moderating effects of sex and age was tested by adding interaction terms to separate multivariable mixed-effects regressions (3-way and 4-way interaction terms between TIME, exposure, Age group, and sex) and by stratifying the models by sex/age group, thus testing main associations within each of the following groups: (1) Younger men $(\leq 50 \mathrm{y})$, (2) Older men (>50y), (3) Younger women $(\leq 50 \mathrm{y})$, (4) Older women ( $>50 \mathrm{y})$. A similar approach was adopted for stratification by race: [(1) Whites, (2) African-Americans] (Supplemental Method 2), given the previously reported differences in inflammatory markers by age, sex, and race groups (Mcconnell et al., 2002; Herd et al., 2012; Lu et al., 2017).

Non-random selection of participants may lead to selection bias due to systematic differences between the selected group and the target population on major characteristics. To account for this bias in each mixed-effect regression model, a 2-stage Heckman selection process was carried out. At a first sage, a probit model with binary outcome being selected $=1$ vs. unselected $=0$, was conducted to compute an inverse mills ratio (derived from the predicted probability of being selected, conditional on the covariates baseline age, sex, race, poverty status, and education). At a second stage, this inverse mills ratio was included in the final mixed-effects regression model as a covariate, similar to prior studies (Beydoun et al., 2013).

In all our analyses, we chose a type I error of 0.05 for main effects and 0.10 for interaction terms (Selvin, 2004), prior to correcting for multiple testing. A familywise Bonferroni procedure was adopted for multiple testing correction by accounting only for cognitive test multiplicity with the assumption that each exposure constitutes a distinctive substantive hypothesis.(Hochberg and Tamhane, 1987) Therefore, for main effects, $p<0.0045(0.05 / 11)$ was considered significant, while 2 -way interactions had a critical $p$-values reduced to $(0.10 / 11=0.0090)$. Finally, 3 -way and 4 -way interaction terms had their critical $p$-value reduced to 0.05 . This approach was adopted in at least two previous studies (Beydoun et al., 2015, 2016).

\section{RESULTS}

Baseline study sample characteristics are outlined in Table 1, both by age group and sex, and by race. Older participants ( $>50 \mathrm{y}$, both sexes) had lower educational attainment and income compared to their younger counterparts $(\leq 50 \mathrm{y})$, a differential observed also among African-Americans vs. Whites. Other important differences were a lower literacy (WRAT total score) among African-Americans vs. Whites, a higher prevalence of current smoking and drug use among younger men $(\leq 50 \mathrm{y})$ vs. at least one other group, with a similar pattern observed among African-Americans vs. Whites. Both BMI and HEI-2010 were the lowest in younger men ( $\leq 50 \mathrm{y})$. HEI-2010 suggested a better overall dietary quality among Whites compared with African-Americans. Generally, younger men ( $\leq 50 \mathrm{y})$ reported the least number of chronic conditions, including diabetes, hypertension, dyslipidemia, cardiovascular disease, and inflammatory conditions. African-Americans' prevalence of hypertension and cardiovascular disease were higher than among Whites, while the reverse was true for dyslipidemia. NSAIDs were more likely used by older individuals $(>50 \mathrm{y})$, with no racial differences detected. Except for CRP, all markers reflected higher inflammation among African-Americans. In general, women had more systemic inflammation, particularly compared with younger men $(\leq 50 \mathrm{y})$.

Table S1 shows marked racial disparities in cognitive performance, which persisted over the two waves of data and with poorer performance observed among African-Americans. Of the 11 tests, however, only three indicated a marked decline in cognitive performance over time, while one (MMSE total score) suggested a learning effect among Whites only.

A series of mixed-effects linear regression models (Table 2, Tables S2-S5) were conducted to test our main hypotheses. After correction for multiple testing, a higher baseline ICS was associated with a faster decline on a test of visual memory/visuoconstructive abilities (BVRT), among older men only $(>50 \mathrm{y}$, $\left.\gamma_{11}=+0.17 \pm 0.06, p=0.003\right)$.

Examining individual markers of inflammation (Table S2), multiple-testing adjusted results suggested CRP was associated with poorer baseline mental status among younger women ( $\left.\leq 50 \mathrm{y}, \gamma_{01}=-0.03 \pm 0.01, p=0.002\right)$ and poorer attention among older women ( $\left.>50 \mathrm{y}, \gamma_{01}=-0.024 \pm 0.007, p<0.001\right)$ and African-Americans $\left(\gamma_{01}=-0.029 \pm 0.008, p=0.001\right)$. Nevertheless, CRP was directly associated with an improvement in the same test of attention over time among the AfricanAmerican group $\left(\gamma_{01}=+0.006 \pm 0.002, p=0.002\right)$. For ESR as the main exposure (Table S3), there was a faster decline in verbal memory among older men $\left(>50 \mathrm{y}, \gamma_{11}=-0.008 \pm\right.$ $0.003, P=0.009)$; with poorer baseline performance on tests of attention overall $\left(\gamma_{01}=-0.010 \pm 0.003, P=0.003\right)$ and among African-Americans $\left(\gamma_{01}=-0.013 \pm 0.004, P=0.002\right)$; on a test of verbal fluency among older women $\left(>50 \mathrm{y}, \gamma_{01}=\right.$ $-0.037 \pm 0.013, P=0.004)$ and on a test of executive function, overall $\left(\gamma_{01}=+0.62 \pm 0.21, P=0.004\right)$, among older men $(>50 \mathrm{y}$, $\left.\gamma_{01}=+1.69 \pm 0.53, P=0.001\right)$ and among African-Americans $\left(\gamma_{01}=+0.84 \pm 0.28, P=0.002\right)$. The latter association among others was race-specific $(P<0.05$ for interaction between ESR and race), though no heterogeneity was detected by age and sex. Moreover, a higher baseline serum albumin as an individual marker was linked to slower attention decline among older men ( $\left.>50 \mathrm{y}, \gamma_{11}=+0.329 \pm 0.103, P=0.009\right)$, improvement in executive function in the total population $\left(\gamma_{11}=-6.00\right.$ $\pm 2.26, P=0.008)$, and a better baseline performance in 
TABLE 1 | Selected baseline (Visit 1) and time-dependent study participant characteristics by age group/sex, and by race for HANDLS participants with complete and reliable baseline MMSE scores $(n=2,574)^{\mathrm{a}}$.

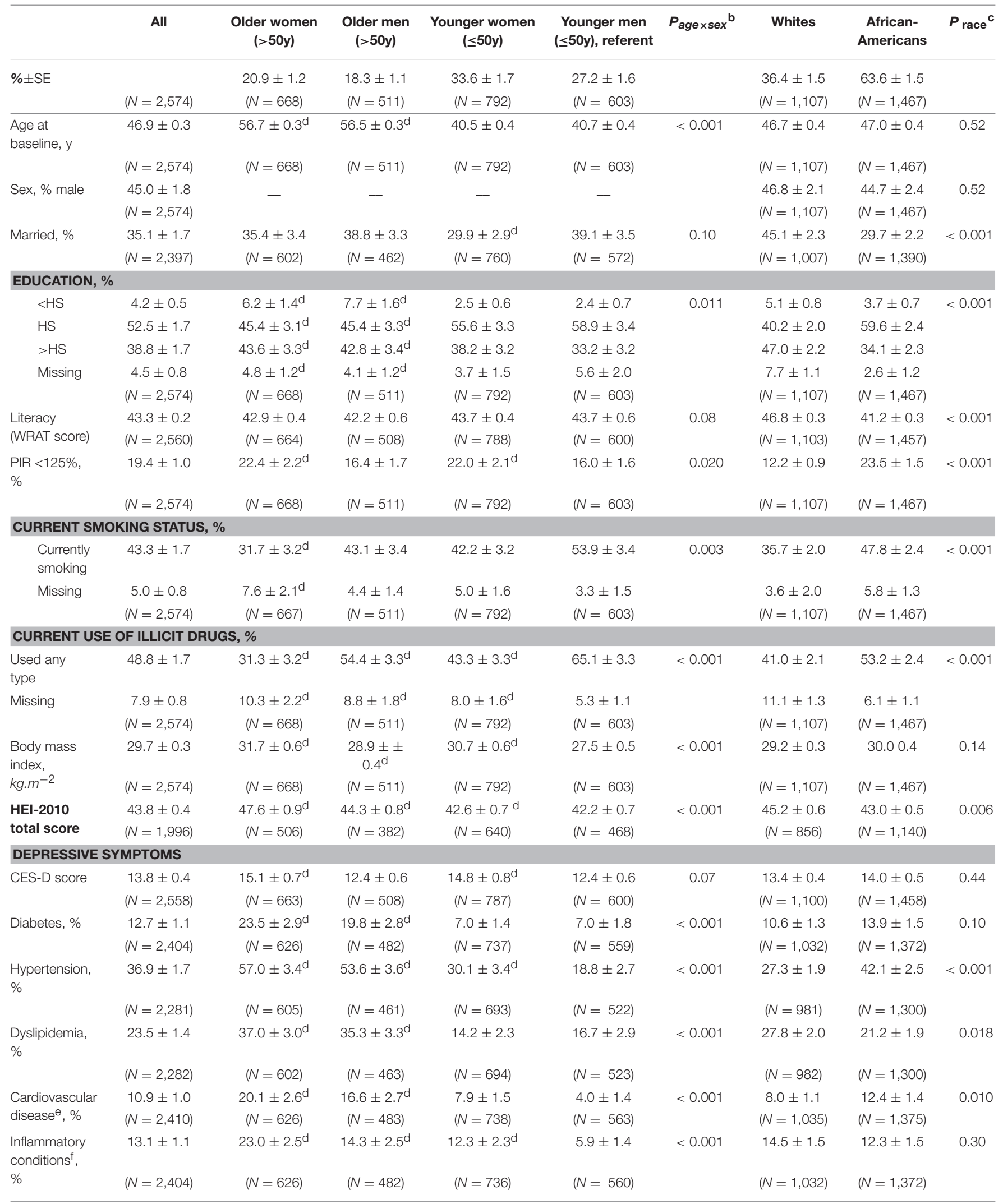


TABLE 1 | Continued

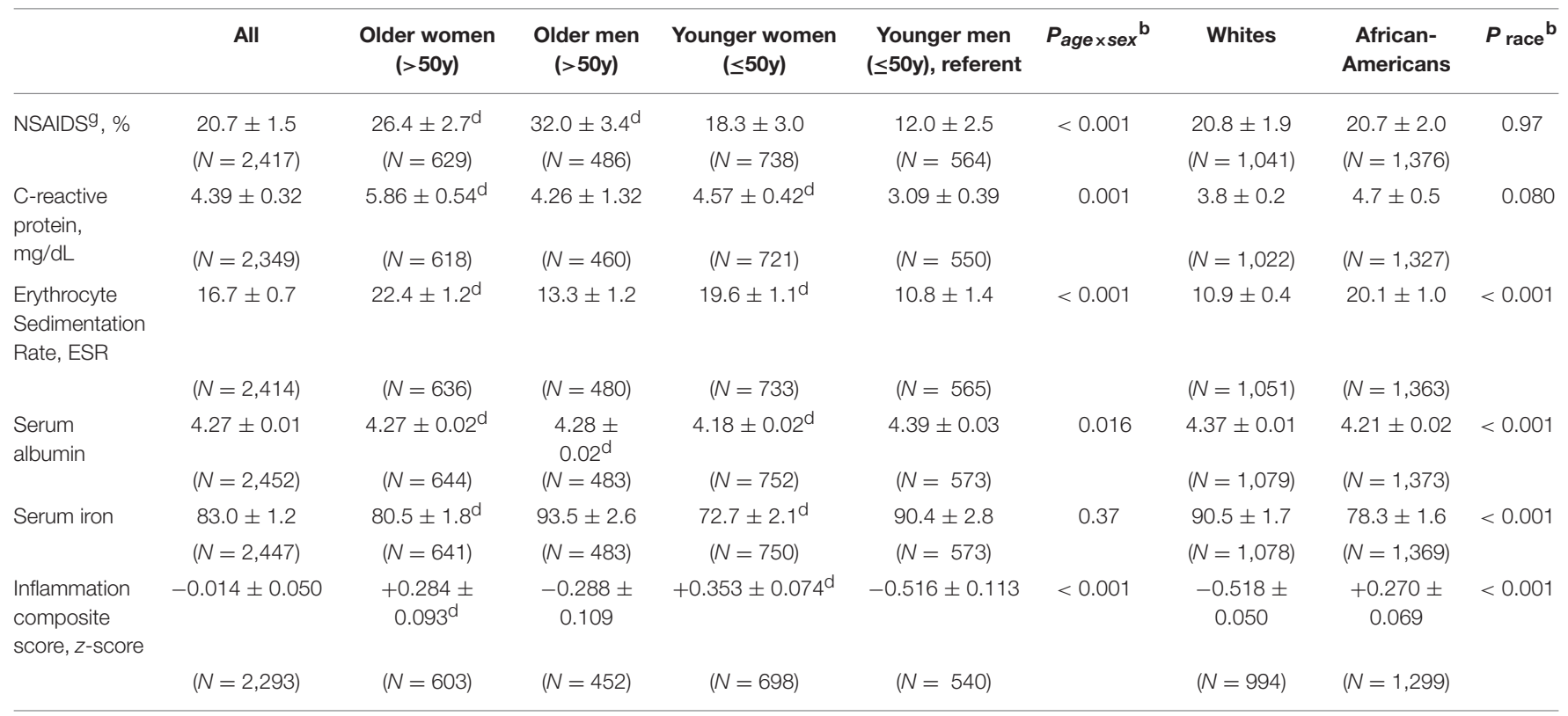

CES-D, Center for Epidemiologic Studies-Depression; MMSE, Mini-Mental State Examination; PIR, poverty income ratio; WRAT, Wide Range Achievement Test.

a Values are weighted mean \pm SEM or percent \pm SEP. Largest sample size is $N=2,574$.

${ }^{b} P$-value was based on linear regression models when row variable is continuous (svy:reg) with sex/age group coded as continuous variable ( $0=y o u n g e r$ men, $1=y o u n g e r$ women, 2=older men, 3=older women) and design-based F-test when row variable is categorical (svy:tab).

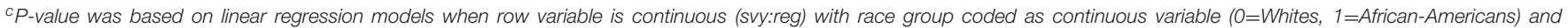
design-based F-test when row variable is categorical (svy:tab).

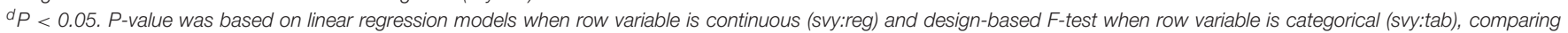
each of the sex/age categories to the referent category of younger men $(\leq 50 \mathrm{y})$.

${ }^{e}$ Cardiovascular disease include self-reported stroke, congestive heart failure, non-fatal myocardial infarction, or atrial fibrillation.

${ }^{f}$ Inflammatory conditions include multiple sclerosis, systemic lupus, gout, rheumatoid arthritis, psoraiasis, Thyroid disorder and Crohn's disease.

${ }^{g}$ Non-steroidal anti-inflammatory drugs (NSAIDS) include over the counter and prescription drugs in that category.

psychomotor speed among African-Americans $\left(\gamma_{01}=+0.56 \pm\right.$ $0.19, P=0.003)$. There were no significant associations between serum iron and cognitive outcomes. (Table S4) None of the serum iron key associations with cognitive performance, crosssectional or longitudinal, remained significant after correction for multiple testing (Table S5). The relationship between serum albumin and executive function (Trails B) in the total population is illustrated in Figure 1, using predictive margins from the mixed-effects regression model.

\section{DISCUSSION}

To our knowledge, this is the first study of the relationships of systemic inflammation with trajectories of cognitive performance in a large sample of bi-racial urban adults examining associations systematically across age, sex, and race groups. Among key findings, a composite score combining 4 markers of systemic inflammation was associated with faster decline on a test of visual memory/visuo-constructive abilities, among older men only ( $>50 y$ ). Many other associations were detected in the expected direction for all markers except for serum iron, whereby a higher inflammatory status was linked to either worse performance at baseline or faster decline over time for specific age, sex and race groups. Most notably, baseline ESR was associated with a faster decline on verbal memory among older men
( $>50 \mathrm{y})$, whereas serum albumin was linked to slower attention decline among older men (>50y) and over-time improvement in executive function in the total population. In contrast, hs-CRP's associations with cognition were mostly detected at baseline, for global mental status and the domain of attention.

Previous studies have focused on individual markers rather than a composite measure for inflammation, mostly hs-CRP, including many of the recent investigations (Bettcher et al., 2012; Obasi et al., 2012; Trollor et al., 2012; Arfanakis et al., 2013; O’bryant et al., 2013; Yarchoan et al., 2013; Krogh et al., 2014; Lima et al., 2014; Metti et al., 2014; Windham et al., 2014; Goldstein et al., 2015; Matsushima et al., 2015; Palta et al., 2015; Gong et al., 2016; Tampubolon, 2016; Tegeler et al., 2016; Watanabe et al., 2016; Hsu et al., 2017; Lai et al., 2017; Walker et al., 2017; Corlier et al., 2018; Hajjar et al., 2018; Warren et al., 2018). In earlier studies conducted between 2003 and 2011, focus was mostly on cognitive performance and decline rather than brain imaging outcomes. In those studies, 18 of 28 selected original studies found a direct relationship between hsCRP and cognitive performance at one point in time (Mangiafico et al., 2006; Roberts et al., 2009, 2010; Hoshi et al., 2010; Noble et al., 2010; O’bryant et al., 2010; Canon and Crimmins, 2011) or decline over time (or incident cognitive impairment) (Yaffe et al., 2003; Engelhart et al., 2004; Komulainen et al., 2007; Hoth et al., 2008; Locascio et al., 2008; Luciano et al., 2009; Marioni 
TABLE 2 | Cognitive performance test scores by inflammation composite score (ICS), stratified by age group/sex and by race, for HANDLS participants with complete and reliable baseline and/or follow-up cognitive scores: mixed-effects regression models ${ }^{a}$.

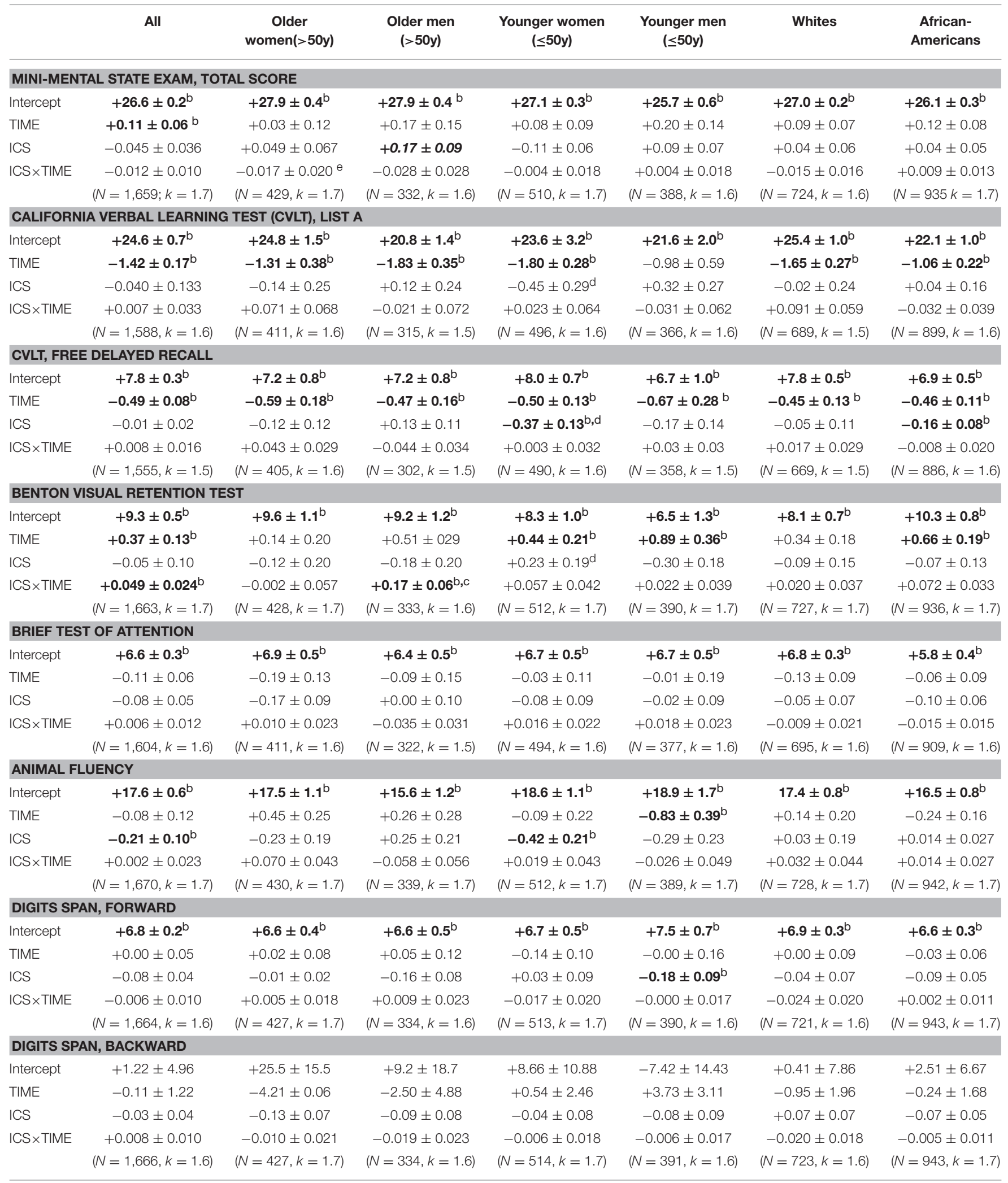


TABLE 2 | Continued

\begin{tabular}{|c|c|c|c|c|c|c|c|}
\hline & All & $\begin{array}{c}\text { Older } \\
\text { women }(>50 y)\end{array}$ & $\begin{array}{l}\text { Older men } \\
\qquad(>50 y)\end{array}$ & $\begin{array}{c}\text { Younger women } \\
(\leq 50 \mathrm{y})\end{array}$ & $\begin{array}{c}\text { Younger men } \\
\quad(\leq 50 \mathrm{y})\end{array}$ & Whites & $\begin{array}{l}\text { African- } \\
\text { Americans }\end{array}$ \\
\hline \multicolumn{8}{|c|}{ CLOCK, COMMAND } \\
\hline TIME & $-0.05 \pm 0.04$ & $-0.12 \pm 0.08$ & $+0.02 \pm 0.09$ & $-0.08 \pm 0.05^{b}$ & $+0.02 \pm 0.05$ & $-0.05 \pm 0.06$ & $-0.04 \pm 0.05$ \\
\hline ICS & $-0.01 \pm 0.03$ & $+0.06 \pm 0.05$ & $-0.06 \pm 0.05^{\mathrm{e}}$ & $-0.004 \pm 0.014^{d}$ & $+0.07 \pm 0.05$ & $+0.04 \pm 0.04$ & $-0.03 \pm 0.03$ \\
\hline \multicolumn{8}{|c|}{ TRAILMAKING TEST, PART A } \\
\hline Intercept & $+35.3 \pm 4.1^{b}$ & $+35.2 \pm 4.1^{\mathrm{b}}$ & $+42.6 \pm 8.6^{b}$ & $+34.1 \pm 21.5^{\mathrm{b}}$ & $+37.6 \pm 11.7^{b}$ & $+20.2 \pm 2.8^{\mathrm{b}}$ & $+47.9 \pm 7.8^{\mathrm{b}}$ \\
\hline TIME & $+2.32 \pm 1.24$ & $+23.42 \pm 7.04^{b}$ & $+1.30 \pm 2.60$ & $-4.93 \pm 6.56$ & $+1.95 \pm 3.98$ & $+1.03 \pm 0.66$ & $+2.93 \pm 2.20$ \\
\hline ICS & $+0.01 \pm 0.74$ & $-0.78 \pm 1.77$ & $-1.42 \pm 1.54$ & $+0.64 \pm 1.05$ & $+0.24 \pm 1.54$ & $-0.23 \pm 0.42$ & $+0.23 \pm 0.36$ \\
\hline ICS $\times$ TIME & $+0.142 \pm 0.230$ & $+0.865 \pm 0.582$ & $+0.277 \pm 0.511$ & $+0.001 \pm 0.314$ & $-0.139 \pm 0.483$ & $-0.067 \pm 0.106$ & $+0.232 \pm 0.364$ \\
\hline ICS & $+4.16 \pm 2.78$ & $-2.00 \pm 5.65$ & $+17.00 \pm 6.65^{b}$ & $+0.46 \pm 5.0$ & $+2.32 \pm 4.81$ & $+0.08 \pm 3.90$ & $+8.09 \pm 3.78^{b}$ \\
\hline \multirow[t]{2}{*}{ ICS $\times$ TIME } & $-0.389 \pm 0.608$ & $+2.159 \pm 1.365$ & $-0.926 \pm 1.725$ & $+0.363 \pm 1.136$ & $-0.322 \pm 0.711$ & $-0.538 \pm 0.787$ & $+0.686 \pm 0.851$ \\
\hline & $(N=1,634, k=1.6)$ & $(N=425, k=1.6)$ & $(N=316, k=1.6)$ & $(N=510, k=1.7)$ & $(N=383, k=1.6)$ & $(N=715, k=1.6)$ & $(N=919, k=1.6)$ \\
\hline
\end{tabular}

CES-D, Center for Epidemiologic Studies-Depression; ICS, Inflammation composite score; MMSE, Mini-Mental State Examination; NSAIDs, Non-steroidal anti-inflammatory drugs; PIR, poverty income ratio; WRAT, Wide Range Achievement Test.

${ }^{a}$ Most cognitive test scores were in the direction of higher score=better performance, except for BVRT (total errors), and Trailmaking Test both parts (expressed in seconds). Models were controlled for: age (centered at 50 y), sex, race, poverty status, education, marital status, literacy, current smoking status, current drug use, body mass index (BMI, centered at 30), CES-D total score (centered at 15), HEl-2010 (centered at 40), self-reported diabetes, hypertension, high cholesterol, cardiovascular disease, inflammatory conditions, NSAIDs, and the inverse mills ratio. All covariates were interacted with TIME. All inverse mills ratios were centered at zero, except for DS-B, Trails $A$ and $B$ for whom the inverse mills ratio was centered at its mean.

${ }^{b} P<0.05$ for null hypothesis that $\gamma=0{ }^{c} P<0.009$ for null hypothesis that $\gamma=0$ for interaction between ICS and TIME. ${ }^{d} p<0.05$ for null hypothesis of no by sex and Age group, based on 3-way and 4-way interaction terms with ICS and TIME.

${ }^{e} p<0.05$ for null hypothesis of no by race, based on 2-way and 3-way interaction terms with ICS and TIME.

et al., 2009; Mooijaart et al., 2011). Our study corroborated the former finding more than the latter, particularly for global mental status and the domain of attention. In previous studies, when a large battery of cognitive tests was used, hs-CRP were adversely linked to domains of verbal memory (Komulainen et al., 2007; Mooijaart et al., 2011), attention (Hoth et al., 2008), psychomotor speed (Hoth et al., 2008; Canon and Crimmins, 2011; Mooijaart et al., 2011), executive function (Hoth et al., 2008; Wersching et al., 2010), and visuo-spatial function (Noble et al., 2010), With the exception of the Whitehall II study (Gimeno et al., 2008) most of those earlier studies were conducted on older adults with mean ages $>60 \mathrm{y}$ at baseline, as opposed to studying inflammation during mid-life. Thus, our study adds to the body of evidence of a cross-sectional inverse relationship between hs-CRP levels and cognitive performance in mid-life.

Among the most recent studies conducted as of 2012, at least 10 of 23 have found an association between elevated hs-CRP and worse cognitive, functional and structural brain outcomes. For instance, after 14,180 person-years of followup (UK sample, Age $\geq 75 y$ ), a study found that hs-CRP was associated with worse cognitive performance in the domain of episodic memory particularly among older individuals (Tampubolon, 2016). Similarly, in the Atherosclerosis Risk in Communities (ARIC) study, higher hs-CRP was linked to lower white matter microstructural integrity, particularly among African-Americans (Walker et al., 2017). Delving deeper into AD-relevant brain regions, a recent longitudinal study of 335 elderly subjects found that an elevated baseline hs-CRP predicted thinner regional cortex at year 9, and that CRP itself acted as a mediator in the inverse relationship between baseline metabolic risk and regional cortical thickness (Corlier et al., 2018).

Serum fibrinogen was directly associated with worse cognitive performance in several recent studies (Gabay and Kushner, 1999; Van Oijen et al., 2005; Luciano et al., 2009; Marioni et al., 2009; Wada et al., 2011; Tampubolon, 2016). For instance, in a longitudinal study of 2,312 men and women aged 50 to 80 years participating in the Aspirin for Asymptomatic Atherosclerosis Trial (mean follow-up: 5y), adjusting for baseline cognitive scores and other covariates, baseline fibrinogen predicted decline in several cognitive domains (excluding memory), a finding also observed for hs-CRP (Marioni et al., 2009). However, a large longitudinal study ( $n=6,713$, mean follow-up $5.3 y$ ) found only fibrinogen (and not hs-CRP) was positively associated with incident dementia, $\mathrm{AD}$ and vascular dementia, suggesting fibrinogen's effect on cognition may be hemostatic rather than inflammatory (Van Oijen et al., 2005). Our study indicated that ESR, a proxy measure of fibrinogen, was linked to faster decline 


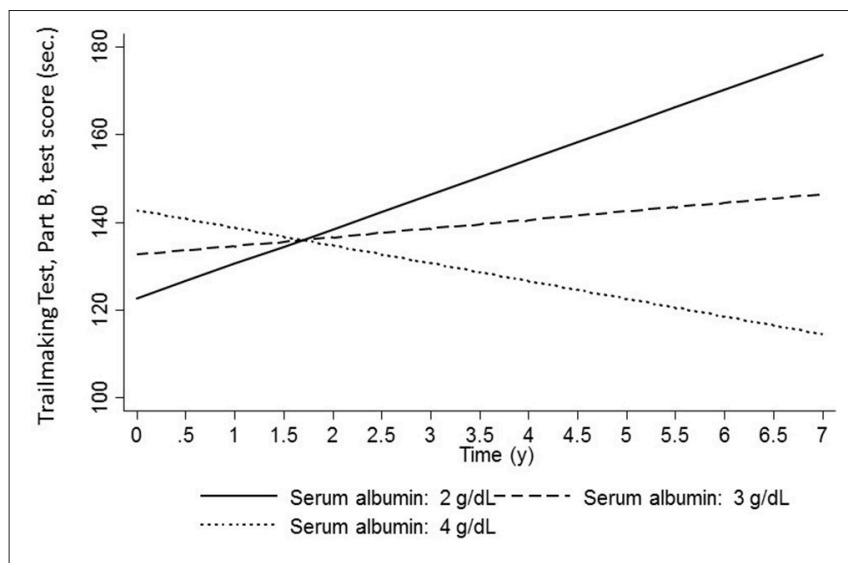

FIGURE 1 | Predictive margins for Trailmaking test B (sec,) by serum albumin levels $(\mathrm{g} / \mathrm{dL})$ : mixed-effects regression models: total population.

on verbal memory among older men, but not in other age/sex or race groups.

Studies that examined the association of serum albumin or iron with cognitive outcomes, though less numerous, were compelling (Dik et al., 2005; Kuo et al., 2007; Vupputuri et al., 2008; Ng et al., 2009; Llewellyn et al., 2010; Onem et al., 2010; Taniguchi et al., 2014; Koyama et al., 2016; Murayama et al., 2017). Specifically, microalbinuria was linked to worse cognitive performance measured by the Digits Symbol Substitution Test (DSST) (tapping into psychomotor speed) in a cross-sectional study of a nationally representative sample of older adults $(\geq 60 \mathrm{y}$, $n=2,049$ ) (Kuo et al., 2007). In a longitudinal study of 1,664 Chinese older adults, lower albumin tertile was associated with greater risk of cognitive impairment at baseline [low, odds ratio $(\mathrm{OR})=2.30,95 \% \mathrm{CI}=1.31-4.03$; medium, $\mathrm{OR}=1.59,95 \%$ $\mathrm{CI}=0.88-2.88]$ vs. high $(P$ for trend $=0.002)$; and with cognitive decline in longitudinal analyses: low, $\mathrm{OR}=1.73$, $95 \%$ CI $=1.18-2.55$; medium, OR $=1.32$, 95\% CI $=0.89-$ 1.95 , vs. high ( $P$ for trend $=0.004$ ). In cognitively unimpaired respondents at baseline (MMSE $\geq 24$ ), similar associations with cognitive decline were observed ( $P$ for trends $<0.002$ ) (Ng et al., 2009). Our study indicated that the putative protective effect of serum albumin on cognition was relevant the total population as well as specific age/sex and race groups wereby a higher baseline serum albumin was linked to slower attention decline among older men improvement in executive function in the total population, and a better baseline performance in psychomotor speed among African-Americans. The latter finding is in line with the cross-sectional study previously described (Kuo et al., 2007). Our findings also highlight the putative protective effect of serum albumin on multiple domains of cognition.

Finally, two large Japanese cohort studies of older adults concluded that baseline serum albumin and baseline measures of iron status (e.g., hemoglobin) were independently associated with cognitive decline over varying follow-up periods (Taniguchi et al., 2014; Murayama et al., 2017). The finding for iron status was not replicated in our study. Moreover, our findings regarding a composite measure for the 4 inflammatory markers indicated that simultaneous increase in hs-CRP and ESR coupled with decreases in serum albumin and iron would lead to a faster decline on the dmain of visual memory/visuo-spatial ability among older men. This finding is novel and suggests biological interactions between inflammatory markers to influence the cognitive trajectory of older men in the domain of visual memroy. High CRP, low albumin and high ESR each had a specific link to cognitive decline for specific groups within this urban adult population. Thus, one cannot generalize to the entire population except for a few instances where Albumin and ESR had an association with cognitive performance and decline in the total sample, specifically in the domain of executive function (i.e. Trails B).

Both acute and chronic events leading to increased systemic inflammation induced by a variety of stimuli reportedly lead to microglia priming, increased production of proinflammatory molecules in the brain, and acceleration of cognitive decline in AD (Holmes et al., 2009; Van Eldik et al., 2016). The hepatic synthesis of acute-phase proteins, such as hs-CRP, is an exquisitely sensitive systemic marker of inflammation, infection, and tissue damage. As reported in our study, increased levels of hs-CRP are found in patients with newly diagnosed AD regardless of age of onset vs. healthy controls suggesting that an amplified neuroinflammatory reaction plays an important role in the pathogenesis and progression of neurocognitive decline in $\mathrm{AD}$ (Song et al., 2015). Low serum albumin levels acting as a negative acute phase reactant, reflect decreased liver function in the elderly and predispose to decreased antioxidant levels which may accelerate cognitive decline in this population (Soriani et al., 1994; Mizrahi et al., 2008; Llewellyn et al., 2010). Chronic anemia and abnormal iron-associated metabolism are well established risk factors for incident AD (Faux et al., 2014) and accelerated cognitive decline (Shah et al., 2011). A number of mechanisms may be at play including decreased plasma iron due to abnormal transferrin desaturation (Hare et al., 2015) and increased levels of oxidized hemoglobin and heme which abnormally bind and colocalize with amyloid-beta senile plaques causing cerebral amyloid angiopathy (Perry et al., 2008; Chuang et al., 2012).

Our study has several notable strengths, including adequate statistical power due to large sample size which allowed stratification by key socio-demographic factors. With two waves of cognitive data, a longitudinal design was possible thus ascertaining temporality of associations. Furthermore, an extensive cognitive battery was administered during those two waves, which enhanced our ability to study a variety of cognitive domains. We also used advanced techniques to adjust for both potential confounders and sample selectivity, while considering sampling weights for baseline covariates in our descriptive analyses. Finally, to study overall effect of systemic inflammation, principal components analysis was conducted to obtain a composite measure based on 4 individual markers.

Nevertheless, our findings are tempered by several limitations. First, despite adjustment for most key confounders, we cannot rule out residual confounding. Second, outcome-related limitations include having only 2 -time points when cognitive performance was measured, limited decline over time possibly due to young age of the cohort, inability to create domains due to lack of factorial invariance across key socio-demographic 
factors. These limitations and others are detailed in previous studies (e.g., Beydoun et al., 2018). Although use of NSAIDs and chronic inflammatory conditions were accounted for in our study, acute inflammation due to injury was not readily available, though it is assumed to be a rare event in our population. In addition, inconsistent findings in terms of cross-sectional and longitudinal relationships between CRP and attention among African-Americans should be further investigated. Moreover, it would be ideal to study these relationships across ApoE4 status, as was done in previous studies. However, genotype data was only available on a sub-sample of African-American HANDLS participants which precluded this type of analysis (Lima et al., 2014; Watanabe et al., 2016).

In sum, there were strong longitudinal and cross-sectional associations between systemic inflammation and cognitive performance, largely among older individuals $(>50 \mathrm{y})$ and African-Americans. Future randomized trials should monitor systemic markers of inflammation and cognitive performance over time.

\section{AUTHOR CONTRIBUTIONS}

MB: conceptualization, plan of analysis, literature search and review, data management, statistical analysis, write-up of the

\section{REFERENCES}

Arfanakis, K., Fleischman, D. A., Grisot, G., Barth, C. M., Varentsova, A., Morris, M. C., et al. (2013). Systemic inflammation in non-demented elderly human subjects: brain microstructure and cognition. PLoS ONE 8:e73107. doi: 10.1371/journal.pone.0073107

Barnes, D. E., and Yaffe, K. (2011). The projected effect of risk factor reduction on Alzheimer's disease prevalence. Lancet Neurol. 10, 819-828. doi: 10.1016/S1474-4422(11)70072-2

Bettcher, B. M., Wilheim, R., Rigby, T., Green, R., Miller, J. W., Racine, C. A., et al. (2012). C-reactive protein is related to memory and medial temporal brain volume in older adults. Brain Behav. Immun. 26, 103-108. doi: 10.1016/j.bbi.2011.07.240

Beydoun, M. A., Beydoun, H. A., Kitner-Triolo, M. H., Kaufman, J. S., Evans, M. K., and Zonderman, A. B. (2013). Thyroid hormones are associated with cognitive function: moderation by sex, race, and depressive symptoms. J. Clin. Endocrinol. Metab. 98, 3470-3481. doi: 10.1210/jc.2013-1813

Beydoun, M. A., Beydoun, H. A., Rostant, O. S., Dore, G. A., Fanelli-Kuczmarski, M. T., Evans, M. K., et al. (2015). Thyroid hormones are associated with longitudinal cognitive change in an urban adult population. Neurobiol. Aging 36, 3056-3066. doi: 10.1016/j.neurobiolaging.2015.08.002

Beydoun, M. A., Canas, J. A., Dore, G. A., Beydoun, H. A., Rostant, O. S., Fanelli-Kuczmarski, M. T., et al. (2016). Serum uric acid and its association with longitudinal cognitive change among urban adults. J. Alzheimers Dis. 52, 1415-1430. doi: 10.3233/JAD-160028

Beydoun, M. A., Hossain, S., Fanelli-Kuczmarski, M. T., Beydoun, H. A., Canas, J. A., Evans, M. K., et al. (2018). Vitamin D status and intakes and their association with cognitive trajectory in a longitudinal study of urban adults. J. Clin. Endocrinol. Metab. 103, 1654-1668. doi: 10.1210/jc.2017-02462

Canon, M. E., and Crimmins, E. M. (2011). Sex differences in the association between muscle quality, inflammatory markers, and cognitive decline. J. Nutr. Health Aging 15, 695-698. doi: 10.1007/s12603-011-0340-x

Chuang, J. Y., Lee, C. W., Shih, Y. H., Yang, T., Yu, L., and Kuo, Y. M. (2012). Interactions between amyloid-beta and hemoglobin: implications for amyloid plaque formation in Alzheimer's disease. PLoS ONE 7:e33120. doi: 10.1371/journal.pone.0033120 manuscript, revision of the manuscript; GD and HB: Literature search and review, write-up of parts of the manuscript, revision of the manuscript; J-AC and HL: Literature review, write-up of parts of the manuscript, revision of manuscript; ME: Data acquisition, write-up of parts of the manuscript, revision of the manuscript; AZ: Data acquisition, plan of analysis, write-up of parts of the manuscript, revision of the manuscript.

\section{FUNDING}

This study was entirely supported by the National Institute on Aging, Intramural Research Program (NIA/NIH/IRP).

\section{ACKNOWLEDGMENTS}

The authors would like to thank Salman Tajuddin and Ola Rostant for their internal review of the manuscript.

\section{SUPPLEMENTARY MATERIAL}

The Supplementary Material for this article can be found online at: https://www.frontiersin.org/articles/10.3389/fnagi. 2018.00313/full\#supplementary-material

Corlier, F., Hafzalla, G., Faskowitz, J., Kuller, L. H., Becker, J. T., Lopez, O. L., et al. (2018). Systemic inflammation as a predictor of brain aging: contributions of physical activity, metabolic risk, and genetic risk. Neuroimage 172, 118-129. doi: 10.1016/j.neuroimage.2017.12.027

Dik, M. G., Jonker, C., Hack, C. E., Smit, J. H., Comijs, H. C., and Eikelenboom, P. (2005). Serum inflammatory proteins and cognitive decline in older persons. Neurology 64, 1371-1377. doi: 10.1212/01.WNL.0000158281.08946.68

Engelhart, M. J., Geerlings, M. I., Meijer, J., Kiliaan, A., Ruitenberg, A., Van Swieten, J. C., et al. (2004). Inflammatory proteins in plasma and the risk of dementia: the rotterdam study. Arch. Neurol. 61, 668-672. doi: 10.1001/archneur.61.5.668

Evans, M. K., Lepkowski, J. M., Powe, N. R., Laveist, T., Kuczmarski, M. F., and Zonderman, A. B. (2010). Healthy aging in neighborhoods of diversity across the life span (HANDLS): overcoming barriers to implementing a longitudinal, epidemiologic, urban study of health, race, and socioeconomic status. Ethn. Dis. 20, 267-275.

Faux, N. G., Rembach, A., Wiley, J., Ellis, K. A., Ames, D., Fowler, C. J., et al. (2014). An anemia of Alzheimer's disease. Mol. Psychiatry 19, 1227-1234. doi: $10.1038 / \mathrm{mp} .2013 .178$

Gabay, C., and Kushner, I. (1999). Acute-phase proteins and other systemic responses to inflammation. N. Engl. J. Med. 340, 448-454. doi: 10.1056/NEJM199902113400607

Gimeno, D., Kivimaki, M., Brunner, E. J., Elovainio, M., De Vogli, R., Steptoe, A., et al. (2009). Associations of C-reactive protein and interleukin6 with cognitive symptoms of depression: 12-year follow-up of the Whitehall II study. Psychol. Med. 39, 413-423. doi: 10.1017/S00332917080 03723

Gimeno, D., Marmot, M. G., and Singh-Manoux, A. (2008). Inflammatory markers and cognitive function in middle-aged adults: the Whitehall II study. Psychoneuroendocrinology 33, 1322-1334. doi: 10.1016/j.psyneuen.2008.07.006

Goldstein, F. C., Zhao, L., Steenland, K., and Levey, A. I. (2015). Inflammation and cognitive functioning in African Americans and Caucasians. Int. J. Geriatr. Psychiatry 30, 934-941. doi: 10.1002/gps.4238

Gong, C., Wei, D., Wang, Y., Ma, J., Yuan, C., Zhang, W., et al. (2016). A meta-analysis of C-reactive protein in patients with alzheimer's disease. Am. J. Alzheimers Dis. Other Dement. 31, 194-200. doi: 10.1177/1533317515602087 
Gu, Y., Manly, J. J., Mayeux, R. P., and Brickman, A. M. (2018). An inflammation-related nutrient pattern is associated with both brain and cognitive measures in a multiethnic elderly population. Curr. Alzheimer Res. 15, 493-501. doi: 10.2174/1567205015666180101145619

Hajjar, I., Hayek, S. S., Goldstein, F. C., Martin, G., Jones, D. P., and Quyyumi, A. (2018). Oxidative stress predicts cognitive decline with aging in healthy adults: an observational study. J. Neuroinflammation 15, 17. doi: 10.1186/s12974-017-1026-z

Hare, D. J., Doecke, J. D., Faux, N. G., Rembach, A., Volitakis, I., Fowler, C. J., et al. (2015). Decreased plasma iron in Alzheimer's disease is due to transferrin desaturation. ACS Chem. Neurosci. 6, 398-402. doi: 10.1021/cn5003557

Herd, P., Karraker, A., and Friedman, E. (2012). The social patterns of a biological risk factor for disease: race, gender, socioeconomic position, and C-reactive protein. J. Gerontol. B Psychol. Sci. Soc. Sci. 67, 503-513. doi: 10.1093/geronb/gbs048

Hochberg, Y., and Tamhane, A. C. (1987). Multiple Comparison Procedures. New York, NY: Wiley. doi: 10.1002/9780470316672

Holmes, C., Cunningham, C., Zotova, E., Woolford, J., Dean, C., Kerr, S., et al. (2009). Systemic inflammation and disease progression in Alzheimer disease. Neurology 73, 768-774. doi: 10.1212/WNL.0b013e3181b6bb95

Hoshi, T., Yamagami, H., Furukado, S., Miwa, K., Tanaka, M., Sakaguchi, M., et al. (2010). Serum inflammatory proteins and frontal lobe dysfunction in patients with cardiovascular risk factors. Eur. J. Neurol. 17, 1134-1140. doi: $10.1111 / j .1468-1331.2010 .02990 . x$

Hoth, K. F., Haley, A. P., Gunstad, J., Paul, R. H., Poppas, A., Jefferson, A. L., et al. (2008). Elevated C-reactive protein is related to cognitive decline in older adults with cardiovascular disease. J. Am. Geriatr. Soc. 56, 1898-1903. doi: 10.1111/j.1532-5415.2008.01930.x

Hsu, P. F., Pan, W. H., Yip, B. S., Chen, R. C., Cheng, H. M., and Chuang, S. Y. (2017). C-Reactive protein predicts incidence of dementia in an elderly asian community cohort. J. Am. Med. Dir. Assoc. 18, 277-277 e211. doi: 10.1016/j.jamda.2016.12.006

Hsuchou, H., Kastin, A. J., Mishra, P. K., and Pan, W. (2012). C-reactive protein increases BBB permeability: implications for obesity and neuroinflammation. Cell. Physiol. Biochem. 30, 1109-1119. doi: 10.1159/000343302

Ibrahim, J. G., and Molenberghs, G. (2009). Missing data methods in longitudinal studies: a review. Test 18, 1-43. doi: 10.1007/s11749-009-0138-x

Jefferson, A. L., Massaro, J. M., Wolf, P. A., Seshadri, S., Au, R., Vasan, R. S., et al. (2007). Inflammatory biomarkers are associated with total brain volume: the Framingham Heart Study. Neurology 68, 1032-1038. doi: 10.1212/01.wnl.0000257815.20548.df

Komulainen, P., Lakka, T. A., Kivipelto, M., Hassinen, M., Penttila, I. M., Helkala, E. L., et al. (2007). Serum high sensitivity C-reactive protein and cognitive function in elderly women. Age Ageing 36, 443-448. doi: 10.1093/ageing/afm051

Koyama, T., Kuriyama, N., Ozaki, E., Matsui, D., Watanabe, I., Miyatani, F., et al. (2016). Serum albumin to globulin ratio is related to cognitive decline via reflection of homeostasis: a nested case-control study. BMC Neurol. 16:253. doi: 10.1186/s12883-016-0776-z

Krogh, J., Benros, M. E., Jorgensen, M. B., Vesterager, L., Elfving, B., and Nordentoft, M. (2014). The association between depressive symptoms, cognitive function, and inflammation in major depression. Brain Behav. Immun. 35, 70-76. doi: 10.1016/j.bbi.2013.08.014

Kuo, H. K., Lin, L. Y., and Yu, Y. H. (2007). Microalbuminuria is a negative correlate for cognitive function in older adults with peripheral arterial disease: results from the U.S. National Health and Nutrition Examination Survey 1999-2002. J. Intern. Med. 262, 562-570. doi: 10.1111/j.1365-2796.2007. 01847.x

Lai, K. S. P., Liu, C. S., Rau, A., Lanctot, K. L., Kohler, C. A., Pakosh, M., et al. (2017). Peripheral inflammatory markers in Alzheimer's disease: a systematic review and meta-analysis of 175 studies. J. Neurol. Neurosurg. Psychiatr. 88, 876-882. doi: 10.1136/jnnp-2017-316201

Lima, T. A., Adler, A. L., Minett, T., Matthews, F. E., Brayne, C., Marioni, R. E., et al. (2014). C-reactive protein, APOE genotype and longitudinal cognitive change in an older population. Age Ageing 43, 289-292. doi: 10.1093/ageing/aft193

Llewellyn, D. J., Langa, K. M., Friedland, R. P., and Lang, I. A. (2010). Serum albumin concentration and cognitive impairment. Curr. Alzheimer Res. 7, 91-96. doi: 10.2174/156720510790274392
Locascio, J. J., Fukumoto, H., Yap, L., Bottiglieri, T., Growdon, J. H., Hyman, B. T., et al. (2008). Plasma amyloid beta-protein and C-reactive protein in relation to the rate of progression of Alzheimer disease. Arch. Neurol. 65, 776-785. doi: 10.1001/archneur.65.6.776

Lu, Y., Zhou, S., Dreyer, R. P., Spatz, E. S., Geda, M., Lorenze, N. P., et al. (2017). Sex Differences in inflammatory markers and health status among young adults with acute myocardial infarction: results from the VIRGO (Variation in Recovery: Role of Gender on Outcomes of Young Acute Myocardial Infarction Patients) Study. Circ. Cardiovasc. Qual. Outcomes 10:e003470. doi: 10.1161/CIRCOUTCOMES.116.003470

Luciano, M., Marioni, R. E., Gow, A. J., Starr, J. M., and Deary, I. J. (2009). Reverse causation in the association between C-reactive protein and fibrinogen levels and cognitive abilities in an aging sample. Psychosom. Med. 71, 404-409. doi: 10.1097/PSY.0b013e3181a24fb9

Mangiafico, R. A., Sarnataro, F., Mangiafico, M., and Fiore, C. E. (2006). Impaired cognitive performance in asymptomatic peripheral arterial disease: relation to C-reactive protein and D-dimer levels. Age Ageing 35, 60-65. doi: 10.1093/ageing/afi219

Marioni, R. E., Stewart, M. C., Murray, G. D., Deary, I. J., Fowkes, F. G., Lowe, G. D., et al. (2009). Peripheral levels of fibrinogen, C-reactive protein, and plasma viscosity predict future cognitive decline in individuals without dementia. Psychosom. Med. 71, 901-906. doi: 10.1097/PSY.0b013e3181ble538

Matsushima, J., Kawashima, T., Nabeta, H., Imamura, Y., Watanabe, I., Mizoguchi, Y., et al. (2015). Association of inflammatory biomarkers with depressive symptoms and cognitive decline in a community-dwelling healthy older sample: a 3-year follow-up study. J. Affect. Disord. 173, 9-14. doi: 10.1016/j.jad.2014.10.030

Mcconnell, J. P., Branum, E. L., Ballman, K. V., Lagerstedt, S. A., Katzmann, J. A., and Jaffe, A. S. (2002). Gender differences in C-reactive protein concentrationsconfirmation with two sensitive methods. Clin. Chem. Lab. Med. 40, 56-59. doi: 10.1515/CCLM.2002.011

Metti, A. L., Yaffe, K., Boudreau, R. M., Simonsick, E. M., Carnahan, R. M., Satterfield, S., et al. (2014). Trajectories of inflammatory markers and cognitive decline over 10 years. Neurobiol. Aging 35, 2785-2790. doi: 10.1016/j.neurobiolaging.2014.05.030

Mizrahi, E. H., Blumstein, T., Arad, M., and Adunsky, A. (2008). Serum albumin levels predict cognitive impairment in elderly hip fracture patients. Am. J. Alzheimers Dis. Other Dement. 23, 85-90. doi: 10.1177/1533317507311776

Mooijaart, S. P., Sattar, N., Trompet, S., Polisecki, E., De Craen, A. J., Schaefer, E. J., et al. (2011). C-reactive protein and genetic variants and cognitive decline in old age: the PROSPER study. PLOS ONE 6:e23890. doi: 10.1371/journal.pone.0023890

Murayama, H., Shinkai, S., Nishi, M., Taniguchi, Y., Amano, H., Seino, S., et al. (2017). Albumin, hemoglobin, and the trajectory of cognitive function in community-dwelling older Japanese: a 13-year longitudinal study. J. Prev. Alzheimers Dis. 4, 93-99. doi: 10.14283/jpad.2016.113

Ng, T. P., Niti, M., Feng, L., Kua, E. H., and Yap, K. B. (2009). Albumin, apolipoprotein E-epsilon4 and cognitive decline in communitydwelling Chinese older adults. J. Am. Geriatr. Soc. 57, 101-106. doi: $10.1111 / j .1532-5415.2008 .02086 . \mathrm{x}$

Noble, J. M., Manly, J. J., Schupf, N., Tang, M. X., Mayeux, R., and Luchsinger, J. A. (2010). Association of C-reactive protein with cognitive impairment. Arch. Neurol. 67, 87-92. doi: 10.1001/archneurol.20 09.308

Obasi, C. N., Cruickshanks, K. J., Nondahl, D. M., Klein, B. E., Klein, R., Nieto, F. J., et al. (2012). Association of biomarkers for inflammation, endothelial dysfunction and oxidative stress with cognitive impairment. The Epidemiology of Hearing Loss Study (EHLS). Oxid. Antioxid. Med. Sci. 1, 169-173. doi: 10.5455/oams.031212. br.004

O'bryant, S. E., Johnson, L., Edwards, M., Soares, H., Devous, M. D., Ross, S., et al. (2013). The link between C-reactive protein and Alzheimer's disease among Mexican Americans. J. Alzheimers Dis. 34, 701-706. doi: 10.3233/JAD-122071

O'bryant, S. E., Waring, S. C., Hobson, V., Hall, J. R., Moore, C. B., Bottiglieri, T., et al. (2010). Decreased C-reactive protein levels in Alzheimer disease. J. Geriatr. Psychiatry Neurol. 23, 49-53. doi: 10.1177/0891988709351832

Onem, Y., Terekeci, H., Kucukardali, Y., Sahan, B., Solmazgul, E., Senol, M. G., et al. (2010). Albumin, hemoglobin, body mass index, cognitive and functional 
performance in elderly persons living in nursing homes. Arch. Gerontol. Geriatr. 50, 56-59. doi: 10.1016/j.archger.2009.01.010

Palta, P., Xue, Q. L., Deal, J. A., Fried, L. P., Walston, J. D., and Carlson, M. C. (2015). Interleukin-6 and C-reactive protein levels and 9-year cognitive decline in community-dwelling older women: the women's health and aging study II. J. Gerontol. A Biol. Sci. Med. Sci. 70, 873-878. doi: 10.1093/gerona/glu132

Perry, R. T., Gearhart, D. A., Wiener, H. W., Harrell, L. E., Barton, J. C., Kutlar, A., et al. (2008). Hemoglobin binding to A beta and HBG2 SNP association suggest a role in Alzheimer's disease. Neurobiol. Aging 29, 185-193. doi: 10.1016/j.neurobiolaging.2006.10.017

Roberts, R. O., Geda, Y. E., Knopman, D. S., Boeve, B. F., Christianson, T. J., Pankratz, V. S., et al. (2009). Association of C-reactive protein with mild cognitive impairment. Alzheimers Dement. 5, 398-405. doi: 10.1016/j.jalz.2009.01.025

Roberts, R. O., Geda, Y. E., Knopman, D. S., Cha, R. H., Boeve, B. F., Ivnik, R. J., et al. (2010). Metabolic syndrome, inflammation, and nonamnestic mild cognitive impairment in older persons: a population-based study. Alzheimer Dis. Assoc. Disord. 24, 11-18. doi: 10.1097/WAD.0b013e3181a4485c

Satizabal, C. L., Zhu, Y. C., Mazoyer, B., Dufouil, C., and Tzourio, C. (2012). Circulating IL-6 and CRP are associated with MRI findings in the elderly: the 3C-Dijon Study. Neurology 78, 720-727. doi: 10.1212/WNL.0b013e318248e50f

Selvin, S. (2004). Statistical Analysis of Epidemiologic Data. New York, NY: Oxford University Press.

Shah, R. C., Buchman, A. S., Wilson, R. S., Leurgans, S. E., and Bennett, D. A. (2011). Hemoglobin level in older persons and incident Alzheimer disease: prospective cohort analysis. Neurology 77, 219-226. doi: 10.1212/WNL.0b013e318225aaa9

Song, I.-U., Chung, S.-W., Kim, Y.-D., and Maeng, L.-S. (2015). Relationship between the hs-CRP as non-specific biomarker and Alzheimer's disease according to aging process. Int. J. Med. Sci. 12, 613-617. doi: 10.7150/ijms.12742

Soriani, M., Pietraforte, D., and Minetti, M. (1994). Antioxidant potential of anaerobic human plasma: role of serum albumin and thiols as scavengers of carbon radicals. Arch. Biochem. Biophys. 312, 180-188. doi: 10.1006/abbi.1994.1297

Stacey, D., Ciobanu, L. G., and Baune, B. T. (2017). A systematic review on the association between inflammatory genes and cognitive decline in non-demented elderly individuals. Eur. Neuropsychopharmacol. 27, 568-588. doi: 10.1016/j.euroneuro.2015.12.017

STATA (2017). "Statistics/Data Analysis: Release 15.0". College Station, TX: Stata Corporation.

Taki, Y., Thyreau, B., Kinomura, S., Sato, K., Goto, R., Wu, K., et al. (2013). Correlation between high-sensitivity $\mathrm{C}$-reactive protein and brain gray matter volume in healthy elderly subjects. Hum. Brain Mapp. 34, 2418-2424. doi: $10.1002 / \mathrm{hbm} .22073$

Tampubolon, G. (2016). Repeated systemic inflammation was associated with cognitive deficits in older Britons. Alzheimers Dement. 3, 1-6. doi: 10.1016/j.dadm.2015.11.009

Taniguchi, Y., Shinkai, S., Nishi, M., Murayama, H., Nofuji, Y., Yoshida, H., et al. (2014). Nutritional biomarkers and subsequent cognitive decline among community-dwelling older Japanese: a prospective study. J. Gerontol. A Biol. Sci. Med. Sci. 69, 1276-1283. doi: 10.1093/gerona/glt286

Tegeler, C., O’sullivan, J. L., Bucholtz, N., Goldeck, D., Pawelec, G., SteinhagenThiessen, E., et al. (2016). The inflammatory markers CRP, IL-6, and IL-10 are associated with cognitive function-data from the Berlin Aging Study II. Neurobiol. Aging 38, 112-117. doi: 10.1016/j.neurobiolaging.2015.10.039

Trollor, J. N., Smith, E., Agars, E., Kuan, S. A., Baune, B. T., Campbell, L., et al. (2012). The association between systemic inflammation and cognitive performance in the elderly: the Sydney Memory and Ageing Study. Age 34, 1295-1308. doi: 10.1007/s11357-011-9301-x
Van Eldik, L. J., Carrillo, M. C., Cole, P. E., Feuerbach, D., Greenberg, B. D., Hendrix, J. A., et al. (2016). The roles of inflammation and immune mechanisms in Alzheimer's disease. Alzheimers Dement. 2, 99-109. doi: 10.1016/j.trci.2016.05.001

Van Oijen, M., Witteman, J. C., Hofman, A., Koudstaal, P. J., and Breteler, M. M. (2005). Fibrinogen is associated with an increased risk of Alzheimer disease and vascular dementia. Stroke 36, 2637-2641. doi: 10.1161/01.STR.0000189721.31432.26

Vupputuri, S., Shoham, D. A., Hogan, S. L., and Kshirsagar, A. V. (2008). Microalbuminuria, peripheral artery disease, and cognitive function. Kidney Int. 73, 341-346. doi: 10.1038/sj.ki.5002672

Wada, M., Takahashi, Y., Iseki, C., Kawanami, T., Daimon, M., and Kato, T. (2011). Plasma fibrinogen, global cognitive function, and cerebral small vessel disease: results of a cross-sectional study in community-dwelling Japanese elderly. Intern. Med. 50, 999-1007. doi: 10.2169/internalmedicine.50.4752

Walker, K. A., Power, M. C., Hoogeveen, R. C., Folsom, A. R., Ballantyne, C. M., Knopman, D. S., et al. (2017). Midlife systemic inflammation, late-life white matter integrity, and cerebral small vessel disease: the atherosclerosis risk in communities study. Stroke 48, 3196-3202. doi: 10.1161/STROKEAHA.117.018675

Warren, K. N., Beason-Held, L. L., Carlson, O., Egan, J. M., An, Y., Doshi, J., et al. (2018). Elevated markers of inflammation are associated with longitudinal changes in brain function in older adults. J. Gerontol. A Biol. Sci. Med. Sci. 73, 770-778. doi: 10.1093/gerona/glx199

Watanabe, Y., Kitamura, K., Nakamura, K., Sanpei, K., Wakasugi, M., Yokoseki, A., et al. (2016). Elevated C-reactive protein is associated with cognitive decline in outpatients of a General Hospital: The Project in Sado for Total Health (PROST). Dement. Geriatr. Cogn. Dis. Extra 6, 10-19. doi: 10.1159/000442585

Wersching, H., Duning, T., Lohmann, H., Mohammadi, S., Stehling, C., Fobker, M., et al. (2010). Serum C-reactive protein is linked to cerebral microstructural integrity and cognitive function. Neurology 74, 1022-1029. doi: 10.1212/WNL.0b013e3181d7b45b

Windham, B. G., Simpson, B. N., Lirette, S., Bridges, J., Bielak, L., Peyser, P. A., et al. (2014). Associations between inflammation and cognitive function in African Americans and European Americans. J. Am. Geriatr. Soc. 62, 2303-2310. doi: 10.1111 /jgs.13165

Yaffe, K., Lindquist, K., Penninx, B. W., Simonsick, E. M., Pahor, M., Kritchevsky, S., et al. (2003). Inflammatory markers and cognition in well-functioning African-American and white elders. Neurology 61, 76-80. doi: 10.1212/01.WNL.0000073620.42047.D7

Yarchoan, M., Louneva, N., Xie, S. X., Swenson, F. J., Hu, W., Soares, H., et al. (2013). Association of plasma C-reactive protein levels with the diagnosis of Alzheimer's disease. J. Neurol. Sci. 333, 9-12. doi: 10.1016/j.jns. 2013.05.028

Yin, W., Xu, Z., Sheng, J., Xie, X., and Zhang, C. (2017). Erythrocyte sedimentation rate and fibrinogen concentration of whole blood influences the cellular composition of platelet-rich plasma obtained from centrifugation methods. Exp. Ther. Med. 14, 1909-1918. doi: 10.3892/etm.2017.4724

Conflict of Interest Statement: The authors declare that the research was conducted in the absence of any commercial or financial relationships that could be construed as a potential conflict of interest.

Copyright (C) 2018 Beydoun, Dore, Canas, Liang, Beydoun, Evans and Zonderman. This is an open-access article distributed under the terms of the Creative Commons Attribution License (CC BY). The use, distribution or reproduction in other forums is permitted, provided the original author(s) and the copyright owner(s) are credited and that the original publication in this journal is cited, in accordance with accepted academic practice. No use, distribution or reproduction is permitted which does not comply with these terms. 